\title{
REVIEW
}

\section{Low-density lipoprotein receptor mutational analysis in diagnosis of familial hypercholesterolemia}

\author{
Mafalda Bourbon ${ }^{\mathrm{a}, \mathrm{b}}$, Ana C. Alves ${ }^{\mathrm{a}, \mathrm{b}}$, and Eric J. Sijbrands ${ }^{\mathrm{c}}$
}

\begin{abstract}
Purpose of review
To present up to date evidence on the pathogenicity of low-density lipoprotein receptor $(L D L R)$ variants and to propose a strategy that is suitable for implementation in the clinical work-up of familial hypercholesterolaemia.
\end{abstract}

\section{Recent findings}

More than 1800 variants have been described in the $L D L R$ gene of patients with a clinical diagnosis of familial hypercholesterolaemia; however, less than $15 \%$ have functional evidence of pathogenicity.

\begin{abstract}
Summary
The spectrum of variants in the LDLR identified in patients with clinical familial hypercholesterolaemia is increasing as novel variants are still being reported. However, over $50 \%$ of all $L D L R$ variants need further evidence before they can be confirmed as mutations causing disease. Even with applying the recent American College of Medical Genetics variant classification, a large number of variants are still considered variants of unknown significance. Before obtaining an undisputable confirmation of the effect on the expression and activity of the LDLR, reporting these variants as part of a clinical diagnosis to the patient holds the risk that it might need to be withdrawn in a later stage. An investment should be made to develop functional assays to characterize $L D L R$ variants of unknown significance for a better patient diagnosis and to prevent confusion in the physician's office.
\end{abstract}

\section{Keywords}

functional studies, LDL receptor activity, LDLR gene, patient diagnosis

\section{INTRODUCTION}

More than $90 \%$ of mutations described in patients with familial hypercholesterolaemia are found in the low-density lipoprotein receptor $(L D L R)$ gene [1-4]. Untreated familial hypercholesterolaemia can give rise to marked premature coronary artery disease [5]. Mutations in the genes coding for apolipoprotein B $(A P O B)$ and proprotein convertase subtilisin/kexin type 9 (PCSK9) are rare causes of familial hypercholesterolaemia $(<10 \%)$. The molecular diagnosis of this disorder is required to obtain diagnostic certainty and to perform accurate family screening. However, care should be taken interpreting the result of the genetic diagnosis. In theory, the clinical diagnosis can only be confirmed when a mutation is found and then proven by functional studies to affect LDL metabolism. Variants that lead to the introduction of an early stop codon (nonsense and frameshift alterations) and large rearrangements are known to have a deleterious effect on the function of the LDLR protein. Therefore these mutations are considered to be pathogenic variants without need of further evidence [6]. Nevertheless, the majority of the genetic alterations associated with familial hypercholesterolaemia are in neither of these categories, similar to the majority of other genetic diseases. To overcome this difficulty, the American College of Medical Genetics (ACMG) issued in 2015 [7"'] guidelines for the functional classification of genetic variants that should be taken into account before making a genetic

\footnotetext{
annidade de I\&D, Grupo de Investigação Cardiovascular, Departamento de Promoção da Saúde e Prevenção de Doenças Não Transmissíveis,

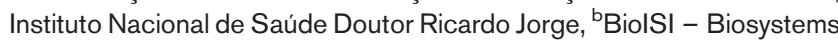
\& Integrative Sciences Institute, Faculdade de Ciências, Universidade de Lisboa, Lisboa, Portugal and ${ }^{\mathrm{C} D e p a r t m e n t}$ of internal Medicine, Erasmus University Rotterdam, Rotterdam, the Netherlands

Correspondence to Mafalda Bourbon, Unidade I\&D, Departamento de Promoção da Saúde e Prevenção de Doenças Não Transmissíveis, Instituto Nacional de Saúde Dr Ricardo Jorge, Av. Padre Cruz, 1649016 Lisboa, Portugal. Tel: +351 217508 126; fax: +351 217526 400; e-mail: mafalda.bourbon@insa.min-saude.pt
}

Curr Opin Lipidol 2017, 28:000-000

DOI:10.1097/MOL.0000000000000404 


\section{KEY POINTS}

- More than 1800 LDLR variants have been described in clinical familial hypercholesterolaemia patients.

- About $50 \%$ of these variants need further evidence to be considered pathogenic.

- American College of Medical Genetics helps on variant classification, but a large number still need functional evaluation.

- Reporting the variants, of which the pathogenicity is unknown, as part of a clinical diagnosis to the patient, holds the risk that it might need to be withdrawn in a later stage.

- Establishment of functional studies for these variants is of utmost importance for familial hypercholesterolaemia diagnosis and to prevent confusion in the physician's office.

diagnosis. In these guidelines, variants are classified as 'pathogenic', 'likely pathogenic', 'variants of unknown significance' (VUS), 'likely benign' and 'benign'. Genetic variants are classified based on a number of criteria; before a variant is considered a disease-causing mutation, support is, for instance, required from structural analyses, evidence from functional studies and in-silico analyses. Following these guidelines, only carriers of variants from the pathogenic and likely pathogenic classes should see their clinical diagnosis confirmed; the remaining patients need to await functional confirmation of the variant's pathogenicity. The purpose of this review is to present up to date evidence on the pathogenicity of $L D L R$ variants and to propose a strategy that is suited for implementation in the clinical work-up of familial hypercholesterolaemia.

\section{GENETIC DIAGNOSIS OF FAMILIAL HYPERCHOLESTEROLAEMIA}

The genetic diagnosis of familial hypercholesterolaemia has been performed, until now, by the study of the all exons and adjacent splicing regions of the $L D L R$ gene by PCR amplification followed by Sanger sequencing, search for large rearrangements by Multiplex Ligation-dependent Probe Amplification (MLPA) analysis and the study of one (part of exon 26) or two fragments (part of exon 26 and part of exon 29) of $A P O B$ gene [2,8-11], also by PCR amplification and Sanger sequencing. PCSK 9 gene is only studied in some laboratories $[12,13]$. However, nextgeneration sequencing (NGS) strategies are changing the genetic diagnosis of familial hypercholesterolaemia, and in the near future, it is expected that, whenever possible, laboratories will be using target sequencing with the complete study of all three familial hypercholesterolaemia genes - LDLR, APOB and PCSK9, and possibly familial hypercholesterolaemia gene phenocopies will be added to such panels (LIPA, APOE, LDLRAP1 and ABCG5/8) because they do not represent a great increase in the overall cost and allow better stratified diagnosis [14].

\section{LOW-DENSITY LIPOPROTEIN RECEPTOR VARIANTS UPDATE}

A compilation of the data available in three public available databases [Leiden Open (source) Variation Database (LOVD)2, LOVD3 and Human Gene Mutation Database] and a bibliography search of the past 10 years up to December 2015 lead to the identification of a total of 1891 variants in $L D L R$ described as causing familial hypercholesterolaemia $\left[15^{-"}\right]$, but ACMG criteria were never applied to majority of variants in these databases. For this analysis, reference sequence NM_000527.4, NG_009060.1 and assembly GRCh37 were used. We now have classified the 1891 reported variants following ACMG guidelines in the five categories (Table 1), and over 40\% need further evidence before they can be confirmed as disease-causing mutations. These numbers do not include reported variants with a minor allele frequency (MAF) greater than $5 \%$. The spectrum of variants in the $L D L R$ identified in patients with clinical familial hypercholesterolaemia is still increasing as novel variants keep on being reported. Increasing awareness of the disorder and access to modern DNA sequence facilities contribute to the growing databases of $L D L R$ variants. For instance, in 2016, 31 novel alterations in the LDLR have been reported mainly in the German, Poland and South African populations [16-18]. Also, during 2015-2016, a total of 37 LDLR variants underwent functional assessment to verify their role in the LDLR cycle $\left[19^{\prime \prime}-24^{\prime \prime}, 25^{*}, 26\right]$ (Table 2).

The majority of the VUS are classified as such because they do not have functional studies and represent $42 \%$ of all variants reported to be cause of familial hypercholesterolaemia. These variants should be the top priority for in-vitro functional assessment. In fact, only 174 out of the 1891 LDLR putative mutations have ever undergone a complete functional study in heterologous cells, which is one of the better suited assays to characterize $L D L R$ putative mutations [27"-], or studies on familial hypercholesterolaemia homozygote patient cells (lymphoblast or fibroblasts) have been performed (Table 3). Due to the high level of evidence obtained in these studies, these were considered level 1 
LDLR variants in diagnosis of familial hypercholesterolemia Bourbon et al.

\begin{tabular}{|c|c|c|c|c|c|c|}
\hline $\begin{array}{l}\text { Alteration type, } \\
\text { structural }\end{array}$ & $\begin{array}{l}\text { Alteration type, } \\
\text { functional }\end{array}$ & Pathogenic & $\begin{array}{l}\text { Likely } \\
\text { pathogenic }\end{array}$ & VUS (FS) & $\begin{array}{l}\text { Likely } \\
\text { benign }\end{array}$ & Benign \\
\hline \multirow[t]{7}{*}{ Indel } & Frameshift & 344 & & $2(0)$ & & \\
\hline & Large rearrangements & 27 & & $134(5)$ & & \\
\hline & In-frame indels & 3 & 43 & $37(1)$ & & \\
\hline & Nonsense & 24 & & & & \\
\hline & Regulatory & & 1 & $7(3)$ & & \\
\hline & Splicing & 19 & 2 & $13(1)$ & & \\
\hline & Missense & & 1 & $3(0)$ & & \\
\hline \multirow[t]{5}{*}{ Point substitution } & Missense & 50 & 325 & 479 (12) & 1 & 4 \\
\hline & Nonsense & 139 & & $5(0)$ & & \\
\hline & Regulatory & & 6 & $28(11)$ & & 2 \\
\hline & Splicing & 95 & 7 & $61(7)$ & 3 & 1 \\
\hline & Synonymous & & & $23(2)$ & 2 & \\
\hline Total & & 701 & 385 & 792 (41) & 6 & 7 \\
\hline
\end{tabular}

Splicing includes all intronic variants.

ACMG, American College of Medical Genetics and Genomics; FS, functional studies; VUS, variant of unknown significance (between brackets are the number of variants with functional studies).

studies (Table 4). Other types of functional studies that do add evidence to the variant pathogenicity, but are not completely informative, have been published for another 85 variants (Table 3). These were considered level 2 studies and include, for example, analysis of number of transcripts for putative slicing variants, but without transcript quantification, and assays performed with cells of familial hypercholesterolaemia heterozygote patients (Table 4). This means that less than $15 \%$ of all variants described have any kind of functional evidence on which they can be classified as a disease-causing mutation.

\section{FUNCTIONAL STUDIES FOR LOW-DENSITY LIPOPROTEIN RECEPTOR MUTATIONS}

Pathogenic $L D L R$ mutations can affect different parts of the LDL receptor cycle: protein synthesis; protein maturation; expression at cell surface and correct insertion in cell membrane; LDL binding; internalization; recycling. The most severe alterations are those that lead to no protein production. These are usually mutations affecting protein expression and synthesis (e.g. when an early stop codon is introduced or a promoter mutation) and also large rearrangements, because no functional protein is produced from those alleles (null allele). Also, a number of missense mutations have less than $2 \%$ LDL receptor activity in in-vitro assays (Table 5), and for this reason are classified as null alleles.

The present-day functional characterization of variants found in $L D L R, A P O B$ or PCSK9 genes is very similar to the ones developed by Brown and Goldstein in order to characterize the LDL receptor cycle comparing LDL receptor activity in normal conditions and in presence of specific mutations. The major difference is that radioactive iodine is replaced by fluorescent labeling of the LDL particle to follow the cycle [28].

The use of flow cytometry allows to follow this fluorescent labelled LDL and to determine the LDLR activity. Another difference is that familial hypercholesterolaemia heterozygote patient cells are no longer used, since the 'normal copy' of the $L D L R$ gene interferes with the mutant allele expression leading to conflicting results [3,27"']. However, true familial hypercholesterolaemia homozygote patient cells are the best human models for functional studies, mostly used in the Dallas collection [29].

\section{Putative point mutation and in-frame deletions/insertions}

In general, to assess $L D L R$ putative mutations, a plasmid containing the LDLR wild-type cDNA (usually pcDNA3) is mutated by in-vitro mutagenesis and transfect into appropriate cell lines (usually CHO-ldlA7 cell line that has been altered to have only residual LDLR activity). After transfecting these cells with the mutated plasmid, the cell line expresses the mutant receptor enabling analyses of the LDLR cycle by following the labelled LDL and observe whether it binds, internalizes and recycles to cell surface or it fails in any of these 


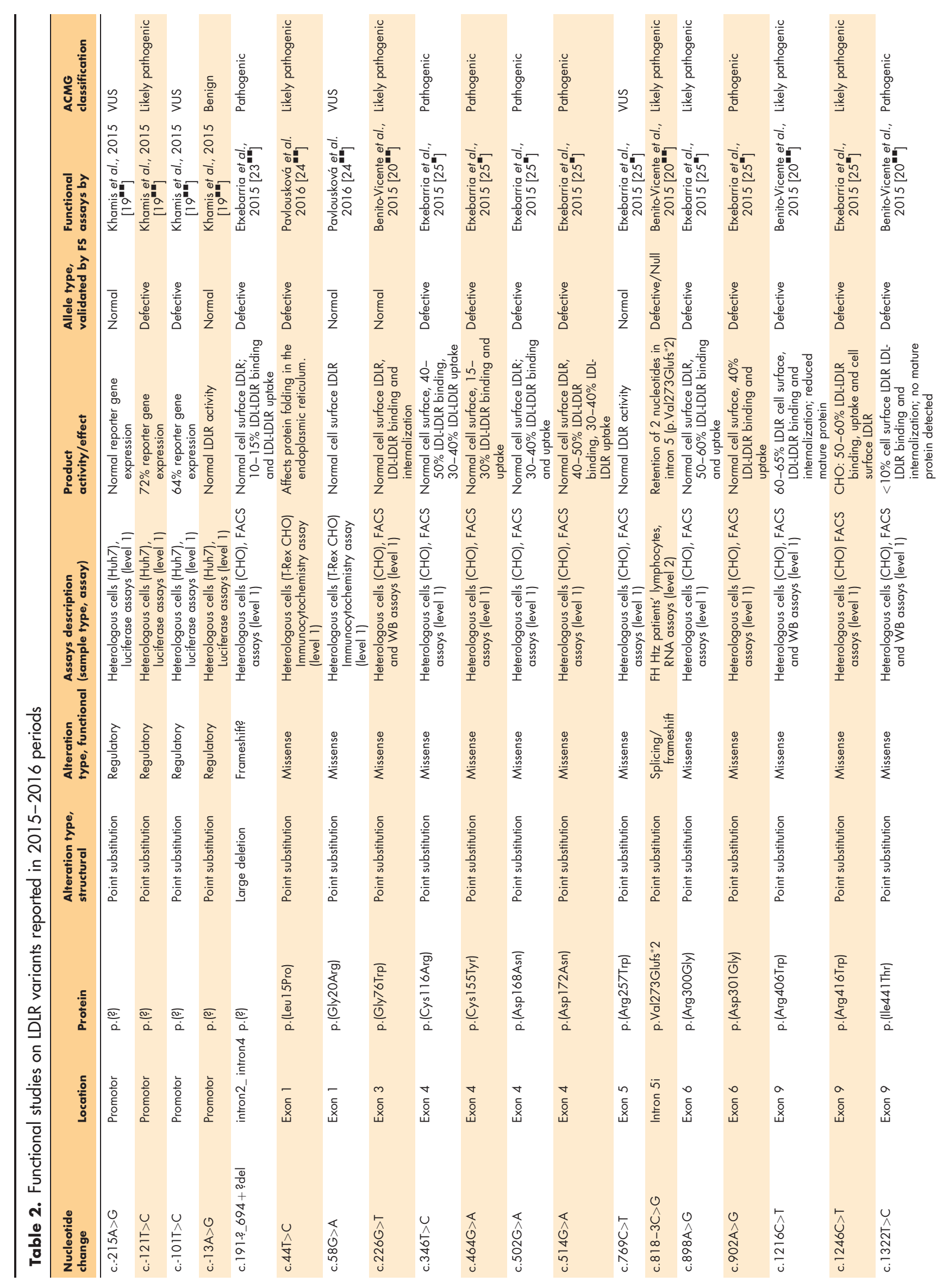




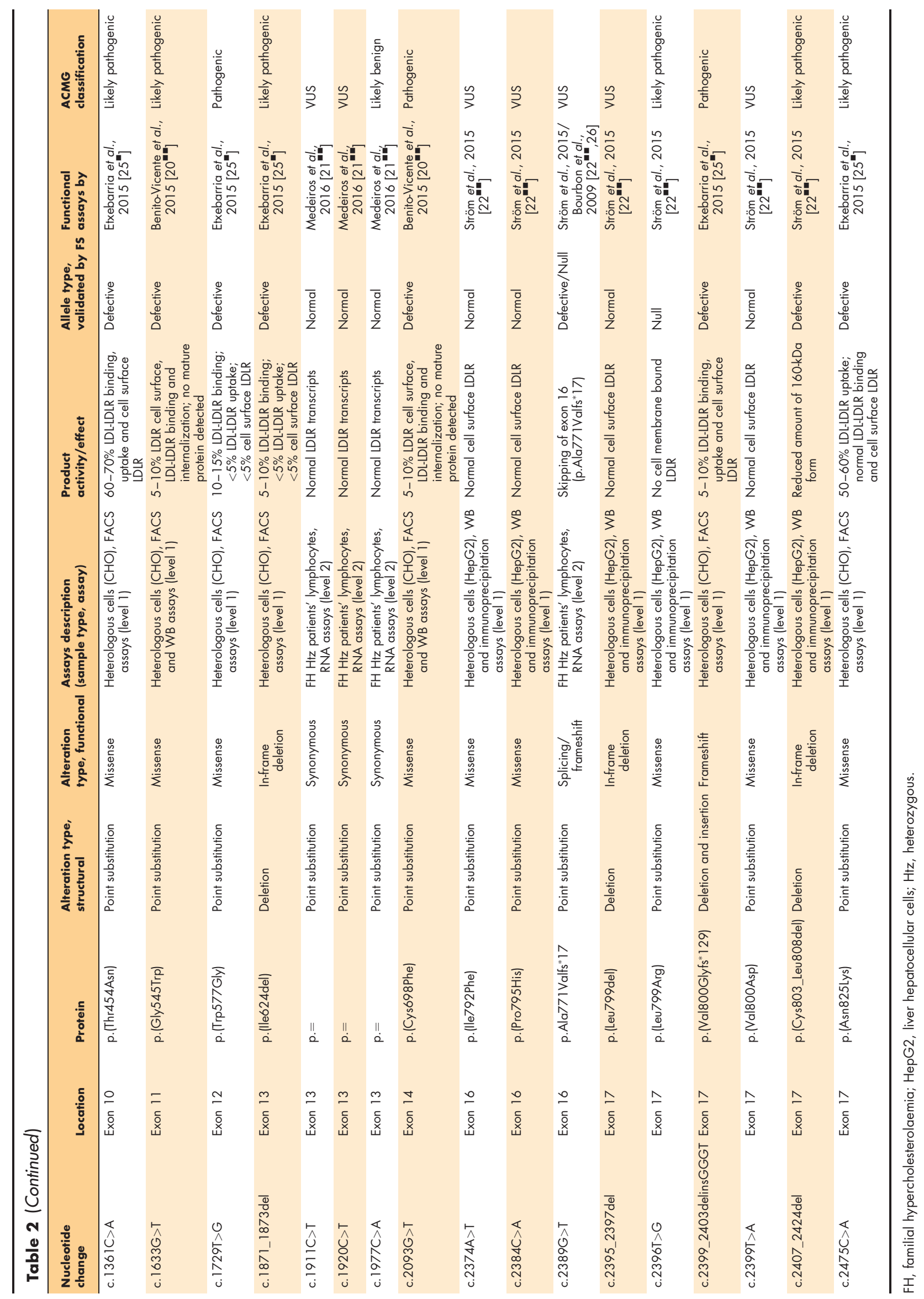


Genetics and molecular biology

Table 3. Number of variants in LDLR by type of variant and existence of level 1 and level 2 functional studies

\begin{tabular}{lrrrr}
\hline Types of variants & LDLR & With FA, level 1 & With FA, level 2 & Without FA \\
\hline Missense & 863 & 86 & 19 & 758 \\
Frameshift & 346 & 7 & 8 & 331 \\
Splicing* & 172 & 24 & 30 & 118 \\
Nonsense & 168 & 15 & 3 & 150 \\
Large rearrangements & 161 & 12 & 4 & 134 \\
In frame delins & 83 & 7 & 0 & 72 \\
Regulatory & 44 & 22 & 2 & 22 \\
Intronic & 29 & 1 & 4 & 26 \\
\hline Synonymous & 25 & 0 & 85 & 21 \\
Total of variants & 1891 & 174 & & 1632 \\
\hline
\end{tabular}

FA, functional studies; LDLR, low-density lipoprotein receptor.

*Only variants up \pm 15 nucleotides into the exon-intron border were included. The remaining were considered intronic variants.

stages, which leads to the exact characterization of the cellular defect. Immunoblotting (western blot) complements all these experiments to test if the LDLR mutant was able or not to go from the precursor to the mature form. If a defect in maturation occurs, the mutant LDLR is retained in the endoplasmic reticulum (ER) and can be seen by confocal microscopy. Finally, flow cytometry, using specific antibodies, will show if the mutant LDLR is expressed at cell surface or not. Additional experiments can determine if the defect is in the recycling pathway (kinetic studies) [20"']. Taken together, these methods allow us to determine if the mutant LDLR is retained in the ER (confocal microscopy studies); not able to form the mature form of the

Table 4. Types of functional studies (FS) included in each level of evidence

\begin{tabular}{lr} 
Type of FS & LDLR \\
\hline Level 1 & \\
Homozygous patients' cells studies & 66 \\
RNA studies with transcript quantification & 19 \\
Heterologous cells' studies & 69 \\
Luciferase studies & 20 \\
Total FS level 1 & 174 \\
Level 2 & \\
Heterozygous patients' cells studies & 38 \\
RNA studies without transcript quantification & 37 \\
Other & 10 \\
Total FS level 2 & 85 \\
Studies not considered & \\
Compound heterozygous patients' cells' studies & 90 \\
Inconclusive studies & 4 \\
Total not considered & 94 \\
\hline
\end{tabular}

protein (western blot); not expressed on the cell surface (flow cytometry studies); not able to bind and internalize LDL (flow cytometry studies); not able to recycle to the cell surface (kinetic studies). Recently, a new class of mutations has been described by Ström et al. [22"'], which is referred to as defective positioning of LDLR on the basolateral cell surface. This can be studied by transient transfection of liver hepatocellular cells with mutant LDLR plasmids and subsequent study of the mutant LDL receptors in cell lysates in media by western blot analysis [22"'].

These experiments enable characterization of the cellular defect and clarify how these mutants affect LDLR activity. If an alteration leads to very small residual $(<2 \%)$ or absent LDLR activity, the alteration is considered to produce a null allele. This means that no functional protein is produced and the patient phenotype is usually severe $[3,36,37]$. On the contrary, if some residual LDLR activity $(\geq 2 \%)$ is detected, the alteration results in a defective allele. The degree to which the mutation affects the LDLR activity can determine patient's phenotype as demonstrated previously [ $\left.20^{-"}\right]$. However, LDLR activity in an individual can be influenced by the environment and/or other alterations in lipid metabolism genes [38]. Therefore, the relationship between LDLR activity and phenotype is not always straightforward. The case of the mutant c.12146C $>\mathrm{T}$, p.(Arg406Trp) is of great interest [20""]. Carriers of this variant have a highly variable expression, resulting in very mild to severe phenotypes. The functional study unraveled the reason of this high variability in phenotypes. The cell expression, binding and internalization were about $60 \%$, which implies that this mutant allele has a substantial residual LDLR activity. In addition, the microscopy studies revealed that these receptors are expressed at 


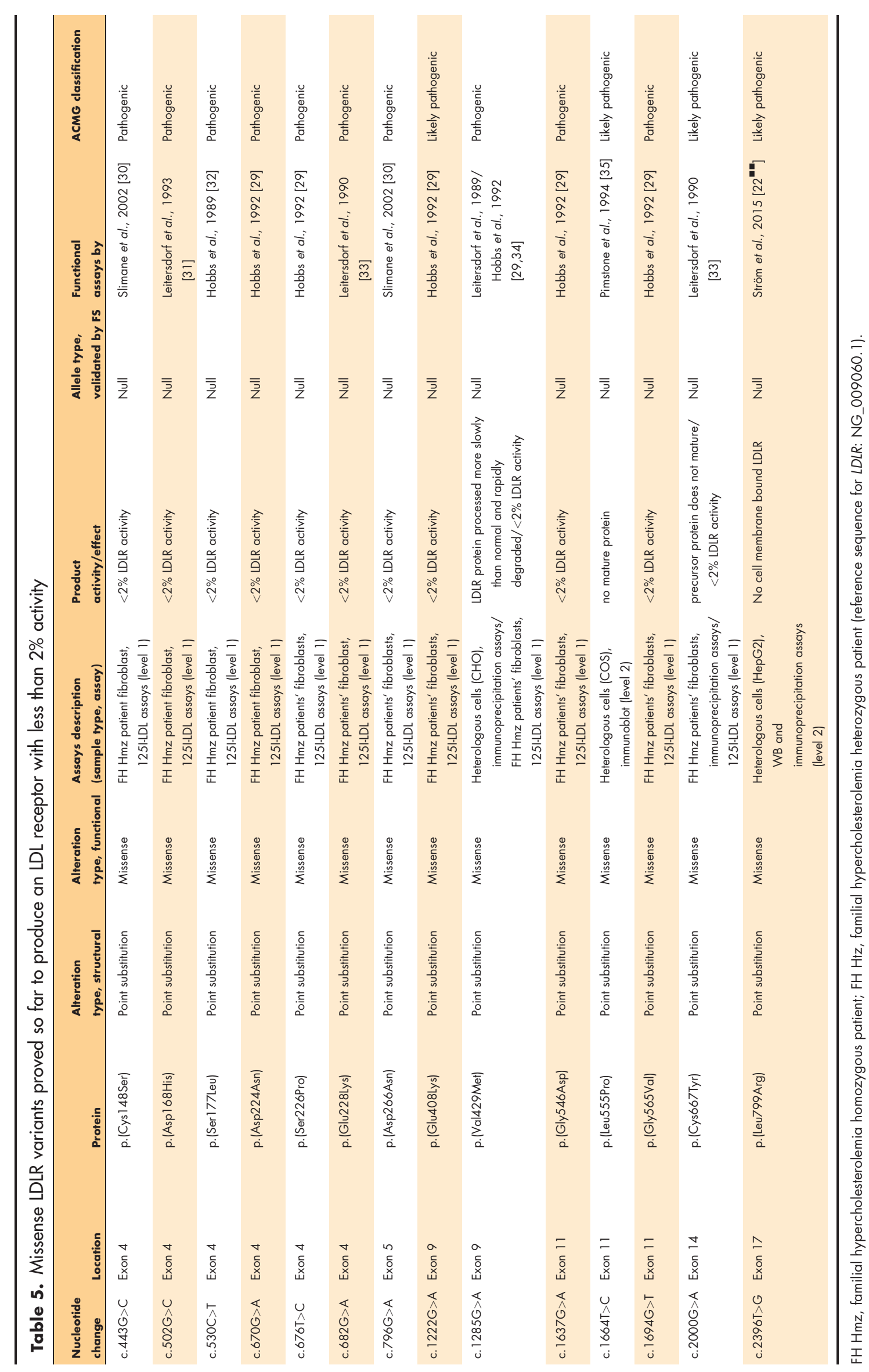


cell surface to a certain level [20"']. This LDLR activity can be sufficient for LDL clearance in case of an adequate healthy lifestyle, but it is dysfunctional in persons who do not adhere to a diet with fat restriction and exercise recommendations. Based on the functional insights from this variant, the clinician might be able to tailor the therapy with a strong recommendation on lifestyle changes, and, if the patient complies, perhaps a low instead of a highdosage statin is sufficient. This was exemplified by the phenotype presented by a number of these mutation carriers [20"'].

\section{Putative splicing variants}

Although the majority of $L D L R$ variants are studied with the methods presented above, putative splicing variants can be studied with less laborious methodology which has been described previously [26]. Since putative splicing variants are suspected to interfere with correct mRNA splicing, it is possible to study a patient's mRNA from lymphocytes to check if one or more transcripts are produced. Several variants have been characterized this way $\left[9,20^{-*}, 26,21^{-*}, 39-41\right]$. For example, using this methodology, it was possible to show that the introduction of two nucleotides (TG duplication) in position c. $190+2 \_190+3$ dup alters the splice region and causes the retention of two nucleotides in intron 2, causing a frameshift and an introduction of a premature stop codon (p.Leu64Cysfs* ${ }^{*} 143$ ) [21"]. But, whereas this method is sufficient to detect if alternative splicing occurs, it does not quantify its effect, so we do not know, for example, if 80 or $20 \%$ of aberrant transcripts are present. This is important, because it will affect the amount of normal protein that is produced, and ultimately LDLR activity. For instance, if only $20 \%$ or less of aberrant transcripts are detected, this alteration may be classified as benign, because at least $80 \%$ of LDLR activity is expected and $80 \%$ is the minimum considered to be necessary for normal LDL clearance $\left[20^{\prime \prime}, 42,43\right]$. In fact, there are patients with splicing mutations who do present with a severe phenotype, whereas other carriers of such variants have mild phenotypes $[39,40]$. We postulate that the difference between these two different groups has to do with transcript quantification that can be determined by real-time PCR. Again, functional studies can help understand the phenotype and add additional information to optimize patient treatment.

It cannot be forgotten that nucleotide changes in the first or the last three nucleotides of an exon can also affect splicing [44], and in-silico analysis should be performed for these kinds of alterations, and, whenever possible, in-vitro analysis as well. Since the number of transcripts is easily obtained by the analysis of the mRNA, these analyses could be performed in nearly all laboratories $[9,26]$. Several variants in these positions have been found all over the world $\left[22^{-*}, 26,45-48\right]$. For example, in the Portuguese familial hypercholesterolaemia study, one case was found in whom the nucleotide change c.2389G $>$ A was predicted to change p.(Val776Leu), but when the splicing machinery was studied, skipping of exon 16 was observed introducing a premature stop codon p.Ala771Valfs*17 [26].

Also, although rare, synonymous alterations can cause splicing defects. The first of these cases has been described in the United Kingdom [49], where a patient was found to have the alteration c.1216C $>$ A, predicted to cause p.(Arg406Arg). Analysis of mRNA from the patient's cells showed that the mutation introduces a new splice site, which is used to the exclusion of the natural splice site and causes a deletion of $31 \mathrm{bp}$ from the mRNA, predicted to introduce premature termination four codons after Arg406 (p.Ser397Thrfs*6). In 2008, a Dutch group published another synonymous variant, c.621C $>\mathrm{G}$, p.(Gly207Gly), as cause of splicing defect [50]. A novel synonymous variant c.1813C $>$ T, p.(Leu605Leu) has been recently characterized as having an effect on splicing [51"], introducing also a premature stop codon.

Another interesting alteration has been described as causing aberrant splicing - c. $2140+86 C>G$ 86C $>\mathrm{G}$ (intron 14) - which activated a cryptic splice site. This alteration causes the insertion of $81 \mathrm{bp}$ in LDLR mRNA and encodes for an in-frame insertion of 27 amino acids in the LDLR, preventing the receptor from leaving the endoplasmic reticulum, probably because of misfolding of the protein. This case highlights the importance of looking for mutations in sites not commonly studied specially in patients without an identifiable mutation in the three genes causing familial hypercholesterolaemia, but with a phenotype very suggestive of familial hypercholesterolaemia [39].

\section{Putative regulatory variants}

Putative regulatory variants can be studied by luciferase assays, and 17 out of the 42 described variants have been characterized this way [19-",52-57]. The luciferase assay is based upon the bioluminescent measurement of firefly luciferase. Briefly, the promoter region is cloned into a plasmid and the mutants are created by sitedirected mutagenesis. Wild-type and mutant plasmids are then transfected into a specific cell line and let to grow. Cells are lysed and luciferase 
activity is then determined using a reporter assay measured in a luminometer.

\section{CONCLUSION}

More than 1800 variants have been described in the $L D L R$ of patients with a clinical diagnosis of familial hypercholesterolaemia; however, less than 15\% have functional evidence supporting pathogenicity. Considering that nonsense, frameshift and large rearrangements have a deleterious effect on a protein, there are still about 1000 variants that need functional characterization. Without definite confirmation of the effect on the expression and activity of the LDLR, reporting these variants as part of a patient's clinical diagnosis carries the risk that the inference of causality might need to be withdrawn in a later stage. The latest ACMG guidelines are a valuable tool for variant classification in order to be able to report the molecular findings to clinicians. However, even when applying the ACMG classification, almost 800 variants need further evidence to be considered pathogenic or likely pathogenic. Establishment of functional studies for these variants is of utmost importance for the diagnosis and to prevent confusion in the physician's office about it.

\section{Acknowledgements}

None.

\section{Financial support and sponsorship}

The $M B$ research has been supported by grants from the Portuguese Cardiology Society, Science and Technology Foundation and BioISI, centre grant UID/MULTI/ 04046/2013, from FCT/MCTES/PIDDAC, Portugal.

\section{Conflicts of interest}

There are no conflicts of interest.

\section{REFERENCES AND RECOMMENDED}

\section{READING}

Papers of particular interest, published within the annual period of review, have been highlighted as:

- of special interest

-1. of outstanding interest

1. Goldstein JL, Hobbs HH, Brown MS. Familial hypercholesterolemia. In: Scriver CR, Beaudet AL, Sly WS, Valle D, editors. The Metabolic and Molecular Bases of Inherited Disease. McGraw-Hill; 1995. pp. 1981-2030.

2. Fouchier SW, Kastelein JJP, Defesche JC. Update of the molecular basis of familial hypercholesterolemia in The Netherlands. Hum Mutat 2005; 26:550556.

3. Soutar AK, Naoumova RP. Mechanisms of disease: genetic causes of familial hypercholesterolemia. Nat Clin Pr Cardiovasc Med 2007; 4:214225.

4. Bourbon M, Alves AC, Medeiros AM, et al. Familial hypercholesterolaemia in Portugal. Atherosclerosis 2008; 196:633-642.

5. Catapano AL, Graham I, De Backer G, et al., Authors/Task Force Members. 2016 ESC/EAS guidelines for the management of dyslipidaemias. Eur Heart J 2016; 37:2999-3058.
6. Wallis $\mathrm{Y}$, Payne $\mathrm{S}$, Mcanulty $\mathrm{C}$, et al. Guidelines updated by the Association for Clinical Genetic Science (formally Clinical Molecular Genetics Society and Association of Clinical Cytogenetics) and the Dutch Society of Clinical Genetic Laboratory Specialists (approved September 2013).

7. Richards S, Aziz N, Bale S, et al. Standards and guidelines for the inter-

- pretation of sequence variants: a joint consensus recommendation of the American College of Medical Genetics and Genomics and the Association for Molecular Pathology. Genet Med 2015; 17:405-424.

ACMG guidelines with the algorithm to classify variants in the different classes.

8. Jannes CE, Santos RD, de Souza Silva PR, et al. Familial hypercholesterolemia in Brazil: cascade screening program, clinical and genetic aspects. Atherosclerosis 2015; 238:101-107.

9. Medeiros AM, Alves AC, Francisco V, Bourbon M. Update of the Portuguese Familial Hypercholesterolaemia Study. Atherosclerosis 2010; 212:553-558.

10. Chiou K-R, Charng M-J. Genetic diagnosis of familial hypercholesterolemia in Han Chinese. J Clin Lipidol 2016; 10:490-496.

11. Goldmann R, Tichý $L$, Freiberger $T$, et al. Genomic characterization of large rearrangements of the LDLR gene in Czech patients with familial hypercholesterolemia. BMC Med Genet 2010; 11:115.

12. Vaca G, Vàzquez A, Magaña MT, et al. Mutational analysis of the LDL receptor and APOB genes in Mexican individuals with autosomal dominant hypercholesterolemia. Atherosclerosis 2011; 218:391-396.

13. Ahmed $W$, Whittall $R$, Riaz $M$, et al. The genetic spectrum of familial hypercholesterolemia in Pakistan. Clin Chim Acta 2013; 421:219-225.

14. Hegele RA, Ban MR, Cao $\mathrm{H}$, et al. Targeted next-generation sequencing in monogenic dyslipidemias. Curr Opin Lipidol 2015; 26:103-113.

15. Chora J, Medeiros AM, Alves AC, et al. Systematic worldwide review of LDLR,

- $\mathrm{APOB}$ and PCSK9 variants associated with familial hypercholesterolaemia using adapted ACMG guidelines for $\mathrm{FH}$ diagnosis. submitted for publication. Systematic review of putative mutations causing $\mathrm{FH}$, adaptation of the ACMG guidelines to classify FH causing variants and distribuition of variants in different classes.

16. Grenkowitz $T$, Kassner U, Wuhle-Demuth $M$, et al. Clinical characterization and mutation spectrum of German patients with familial hypercholesterolemia. Atherosclerosis 2016; 253:88-93.

17. Mickiewicz A, Chmara M, Futema $M$, et al. Efficacy of clinical diagnostic criteria for familial hypercholesterolemia genetic testing in Poland. Atherosclerosis 2016; 249:52-58.

18. Sharifi $M$, Walus-Miarka $M$, Idzior-Walus $B$, et al. The genetic spectrum of familial hypercholesterolemia in south-eastern Poland. Metabolism 2016; 65:48-53.

19. Khamis A, Palmen J, Lench N, et al. Functional analysis of four LDLR 5'UTR

- and promoter variants in patients with familial hypercholesterolaemia. Eur Hum Genet 2015; 23:790-795.

Characterization of several 5'UTR variants found in clinical familial hypercholesterolaemia patients.

20. Benito-Vicente A, Alves AC, Etxebarria A, et al. The importance of an integrated

-1 analysis of clinical, molecular, and functional data for the genetic diagnosis of familial hypercholesterolemia [Internet]. Genet Med 2015; 17:980-988.

The study shows the importance of the integrated analysis for the correct assessment of patients with familial hypercholesterolaemia who can otherwise be misdiagnosed.

21. Medeiros $A M$, Alves $A C$, Bourbon $M$. Mutational analysis of a cohort with

- clinical diagnosis of familial hypercholesterolemia: considerations for genetic diagnosis improvement. Genet Med 2016; 18:316-324.

Description of functional assays of LDLR variants.

22. Ström TB, Laerdahl JK, Leren TP. Mutation p.L799R in the LDLR, which

-1. affects the transmembrane domain of the LDLR, prevents membrane insertion and causes secretion of the mutant LDLR. Hum Mol Genet 2015; 24:58365844

Functional studies characterizing a sixth class of LDLR mutations relating to abnormal insertion of the LDLR in the cell membrane.

23. Etxebarria $A$, Benito-Vicente $A$, Palacios $L$, et al. Functional characterization

-1. and classification of frequent low-density lipoprotein receptor variants. Hum Mutat 2015; 36:129-141.

Functional characterization of several LDLR variants.

24. Pavlousková J, Reblova $K$, Tichy $L$, et al. Functional analysis of the p.(Leu15

- Pro) and p.(Gly20Arg) sequence changes in the signal sequence of LDL receptor. Atherosclerosis 2016; 250:9-14.

Functional characterization of alterations in the signal peptide region showing a pathogenic and a benign variant in the $L D L R$

25. Etxebarria A, Benito-Vicente A, Stef M, et al. Activity-associated effect of LDL

receptor missense variants located in the cysteine-rich repeats. Atherosclerosis $2015 ; 238: 304-312$

Functional studies on LDLR variants located in the cysteine-rich repeats.

26. Bourbon M, Duarte MA, Alves AC, et al. Genetic diagnosis of familial hypercholesterolaemia: the importance of functional analysis of potential splice-site mutations. J Med Genet 2009; 46:352-357.

27. Di Taranto MD, D'Agostino MN, Fortunato G. Functional characterization of

- mutant genes associated with autosomal dominant familial hypercholesterolemia: integration and evolution of genetic diagnosis. Nutr Metab Cardiovasc Dis 2015; 25:979-987.

Review summarizing the different types of functional assays including their advantages and disadvantages. 


\section{Genetics and molecular biology}

28. Etxebarria A, Benito-Vicente A, Alves AC, et al. Advantages and versatility of fluorescence-based methodology to characterize the functionality of LDLR and class mutation assignment. PLoS One 2014; 9:e112677.

29. Hobbs HH, Brown MS, Goldstein JL. Molecular genetics of the LDL receptor gene in familial hypercholesterolemia. Hum Mutat 1992; 1:445-466.

30. Slimane MN, Lestavel S, Clavey V, et al. CYS127S (FH-Kairouan) and D245N (FH-Tozeur) mutations in the LDL receptor gene in Tunisian families with familial hypercholesterolaemia. J Med Genet 2002; 39:e74.

31. Leitersdorf $E$, Reshef $A$, Meiner $V$, et al. A missense mutation in the low density lipoprotein receptor gene causes familial hypercholesterolemia in Sephardic Jews. Hum Genet 1993; 91:141-147.

32. $\mathrm{Ma} \mathrm{YH}$, Bétard $\mathrm{C}$, Roy $\mathrm{M}$, et al. Identification of a second 'French Canadian' LDL receptor gene deletion and development of a rapid method to detect both deletions. Clin Genet 1989; 36:219-228.

33. Leitersdorf E, Tobin EJ, Davignon J, Hobbs HH. Common low-density lipoprotein receptor mutations in the French Canadian population. J Clin Invest 1990; 85:1014-1023.

34. Hobbs HH, Leitersdorf $\mathrm{E}$, Goldstein JL, et al. Multiple crm- mutations in familial hypercholesterolemia. Evidence for 13 alleles, including four deletions. J Clin Invest 1988; 81:909-917.

35. Pimstone SN, Sun X-M, du Souich C, et al. Phenotypic variation in heterozygous familial hypercholesterolemia: a comparison of Chinese patients with the same or similar mutations in the LDL receptor gene in China or Canada. Arterioscler Thromb Vasc Biol 1998; 18:309-315.

36. Nicholls P, Young IS, Graham CA. Genotype/phenotype correlations in familial hypercholesterolaemia. Curr Opin Lipidol 1998; 9:313-317.

37. Graham CA, McClean E, Ward AJM, et al. Mutation screening and genotype:phenotype correlation in familial hypercholesterolaemia. Atherosclerosis 1999; 147:309-316.

38. Soutar AK. Rare genetic causes of autosomal dominant or recessive hypercholesterolaemia. IUBMB Life 2010; 62:125-131.

39. Kulseth MA, Berge KE, Bogsrud MP, Leren TP. Analysis of LDLR mRNA in patients with familial hypercholesterolemia revealed a novel mutation in intron 14, which activates a cryptic splice site. J Hum Genet 2010; 55:676-680.

40. Holla $\varnothing \mathrm{L}$, Nakken $\mathrm{S}$, Mattingsdal M, et al. Effects of intronic mutations in the LDLR gene on premRNA splicing: comparison of wet-lab and bioinformatics analyses. Mol Genet Metab 2009; 96:245-252.

41. Knight BL, Patel DD, Gavigan SJ, Soutar AK. Low-density-lipoprotein-receptor mRNA content of fibroblasts from normal and familial hypercholesterolaemic subjects. Eur J Biochem 1988; 178:555-561.

42. Urdal $\mathrm{P}$, Leren TP, Tonstad S, et al. Flow cytometric measurement of low density lipoprotein receptor activity validated by DNA analysis in diagnosing heterozygous familial hypercholesterolemia. Cytometry 1997; 30:264-268.

43. Ekström U, Abrahamson M, Sveger T, et al. Expression of an LDL receptor allele with two different mutations (E256K and I402T). Mol Pathol 2000; 53:31-36
44. Padgett RA. New connections between splicing and human disease [Internet]. Trends Genet 2012; 28:147-154.

45. Mak YT, Pang CP, Tomlinson B, et al. Mutations in the low-density lipoprotein receptor gene in Chinese familial hypercholesterolemia patients. Arterioscler Thromb Vasc Biol 1998; 18:1600-1605.

46. Zhao Z, Michaely P. Role of an intramolecular contact on lipoprotein uptake by the LDL receptor. Biochim Biophys Acta Mol Cell Biol Lipids 2011; 1811:397-408.

47. Marduel M, Carrié A, Sassolas A, et al. Molecular spectrum of autosoma dominant hypercholesterolemia in France. Hum Mutat 2010; $31:$ E1811E1824.

48. Alonso $R$, Defesche JC, Tejedor $D$, et al. Genetic diagnosis of familia hypercholesterolemia using a DNA-array based platform. Clin Biochem 2009; 42:899-903.

49. Bourbon $M$, Sun $X M$, Soutar AK. A rare polymorphism in the low density lipoprotein (LDL) gene that affects mRNA splicing. Atherosclerosis 2007 195:e17-e20.

50. Defesche JC, Schuurman EJM, Klaaijsen LN, et al. Silent exonic mutations in the low-density lipoprotein receptor gene that cause familial hypercholesterolemia by affecting mRNA splicing. Clin Genet 2008; 73:573-578.

51. Ho CKM, Musa FR, Bell $C$, Walker SW. LDLR gene synonymous mutation

c.1813C $>$ T results in mRNA splicing variation in a kindred with familial hypercholesterolaemia. Ann Clin Biochem 2015; 52:680-684.

Most recent description of another synonimous variant affecting mRNA splicing in familial hypercholesterolaemia.

52. Scholtz CL, Peeters AV, Hoogendijk CF, et al. Mutation $-59 c \rightarrow$ in repeat 2 of the LDL receptor promoter: reduction in transcriptional activity and possible allelic interaction in a South African family with familial hypercholesterolaemia. Hum Mol Genet 1999; 8:2025-2030.

53. Mozas $P$, Galetto $R$, Albajar $M$, et al. A mutation $(-49 \mathrm{C} \rightarrow T)$ in the promoter of the low density lipoprotein receptor gene associated with familial hypercholesterolemia. J Lipid Res 2002; 43:13-18.

54. De Castro-Orós I, Pampin S, Bolado-Carrancio A et al. Functional analysis of LDLR promoter and 5' UTR mutations in subjects with clinical diagnosis of familial hypercholesterolemia. Hum Mutat 2011; 32:868-872.

55. Smith AJ, Ahmed F, Nair D, et al. A functional mutation in the LDLR promote $(-139 \mathrm{C} \rightarrow \mathrm{G})$ in a patient with familial hypercholesterolemia. Eur J Hum Genet 2007; 15:1186-1189.

56. Sun XM, Neuwirth $C$, Wade DP, et al. A mutation (T-45C) in the promoter region of the low-density-lipoprotein (LDL)-receptor gene is associated with a mild clinical phenotype in a patient with heterozygous familial hypercholes terolaemia (FH). Hum Mol Genet 1995; 4:2125-2129.

57. Francová $H$, Trbušek $M$, Zapletalová $P$, Kuhrová $V$. New promoter mutations in the low-density lipoprotein receptor gene which induce familial hypercholesterolaemia phenotype: molecular and functional analysis. J Inherit Metab Dis 2004; 27:523-528. 